\title{
Expert System of Anti-Diabetic Medicine Selection
}

\author{
Andi Hutami Endang \\ Department of Informatic System, Institut Teknologi dan Bisnis Kalla \\ Jl. Urip Sumoharjo Nipah Mall Office Building Lt 5\&6 No.23C, Makassar, Sulawesi Selatan, INDONESIA \\ Email: hutamiendang@kallabs.ac.id
}

\begin{abstract}
The Prediction of World Health Organization (WHO) estimates that in 2030 the number of diabetics in Indonesia reached approximately 21.3 million people. Moreover, the development of medicine consumed by diabetics also varies. In this paper, we present a system that represents a diabetes expert into knowledge based on the domain ontology. The early stage of the system is developing drugs ontology (including functions and contraindications) and patient ontology. Then, matching a weighted ontology will give drugs recommendations that are suitable with the patient's condition. The system can analyze diabetes symptoms to give drugs recommendations to the patient. With large options of diabetes medications that can be consumed, a system can be developed to assist diabetes experts in recommending a diabetes drug that has to be consumed by diabetics. By doing ontology matching, obtained results show that the ontology that has the highest similarity might be a reference to solve the problems in a particular domain. The calculation results of the ontological similarity process showed that patient ontology and contraindicated drugs ontology have a high similarity value which is 0.91 , and it is selected as a solution. The result of this study is good because the system can recommend drugs that match the expert.
\end{abstract}

Key words: diabetes, ontology, expert system, weight ontology

\section{INTRODUCTION}

Diabetes becomes a serious problem in most countries. The prediction of the World Health Organization (WHO) estimates that in 2030 the number of diabetics in Indonesia reached approximately 21.3 million people. In 2000, diabetics in Indonesia just reached 8.4 million people with a margin of 12.9 million people in 30 years. Therefore, it could be concluded that in Indonesia there are approximately 1178 new diabetics every day.

There are three classifications Etiological of Diabetes Mellitus (DM) according to ADA (American Diabetes Association) [1]. There are DM Type 1, DM Type 2, and DM Gestational. In Indonesia, the number of all diabetes type 1 cases has not known in detail. It is caused by the geography of Indonesia or the unsupported genetic factors. Diabetes Mellitus Type 2 includes more than $90 \%$ of the diabetic population numbers, the environmental factors are very significant [2]. If this Diabetes Mellitus is left unchecked, it will lead to serious health problems. To support the treatment process in addition to taking medication, activities are also required to control glucose [3].

The expert system consists of the domain expert, programmers, and knowledge machine. Knowledge machine acquires the knowledge of the domain expert in the problem-solving process. The representation scheme of knowledge is used to store the base of knowledge. The logical deduction and inference in the base of knowledge are used by inference machines to solve the problem [4]. Ontology is one of the technologies adopted from the expert system.

Currently, ontological technology has been used in the search domain and decision-making systems. The EU also promotes the framework ontology-based in creating the Knowledge domain on cardiovascular [5].

Ontology is consisting of Artificial Intelligence (AI) and Machine Language for sharing and resurrecting knowledge. Ontology also included the natural language Processors (NLP) and knowledge representation. Ontology is used to communicate human behavior and computer systems. Furthermore, ontology is used to get information retrieval and knowledge management [6].

Research using weights ontology is used to match the process done by other domains [7]. They are the searching document and the searching base functional web service [8][9][10][11].

A semantic ontology language is used to develop an ontology-based model for diabetic patients to aid doctors in reaching an efficient diagnostic decision about the status of diabetes, the system shows good results [12]. Clinical decision support systems (CDSS) assist doctors or medical practitioners in their daily work, thereby increasing the quality of care given to a patient. Ontology is a good method to encapsulate the concepts and relationships of the term associated with the medical domain [13]. Ontologies are most used in the health domain to make a concise and consistent means of medical terminology. Ontology is a methodology for engaging healthcare and medical information technology[14]. an ontology-based system has been built using the Semantic Web Rule Language (SWRL) and Java Expert System Shell (JESS) libraries to induce potential prescriptions for patients, the system is used to analyze the symptoms of diabetes as well, it is used to determine the drug to be given to the patient[15]. Evidence-based hybrid ontology has been built to help medical practitioners to accomplish inpatient 
glycemic control in diabetic patients for avoiding hypoglycemia [16]. Ontology has an important role in matching contextual data of a patient with that of other healthy patients, while process mining is used for confirming the medical record of the patient to the process model of healthy patients[17]. the automation system has been designed and implemented. The technologies used in this research are the OWL and SWRL. Few types of research explore an automation process of foods recommendation for diabetes patients using the technology of OWL and SWRL. Domain knowledge based on Ontology is needed to process foods composition automatically. However, using SWRL and OWL technology is not enough, because of the accuracy of the words required. A semantic ontology understanding was added using the weighted tree similarity method to specify the composition of foods for diabetic patients[18].

The key to a knowledge base is ontology, it is a wellorganized system of concepts, and it creates something explicit in the domain. Ontology is the specification of conceptualization or it is a logical theory that gives an explicit account that is part of a conceptualization or even a synonym of that conceptualization itself.

\section{SYSTEM ARCHITECTURE}

The system provides the front-end to obtain the result test information from the patient to build their ontology later. That Ontology is weighted and matched later with the drugs ontology. The drugs ontology that has a high similar value is the drugs solution recommended to be consumed by the patients. The structure of the antidiabetic medicines selection system is shown in Figure 1.

1. The patient ontology and the drugs ontology are built by using protégé and the drugs ontology is stored in the repository.

2. Formula (1) is used to calculate the weight of each ontology.

3. Formula (2) is used to calculate the similarity of each drug ontologies with the patient ontology.

4. Finally, the drugs ontology has the highest similarity chosen as a solution.

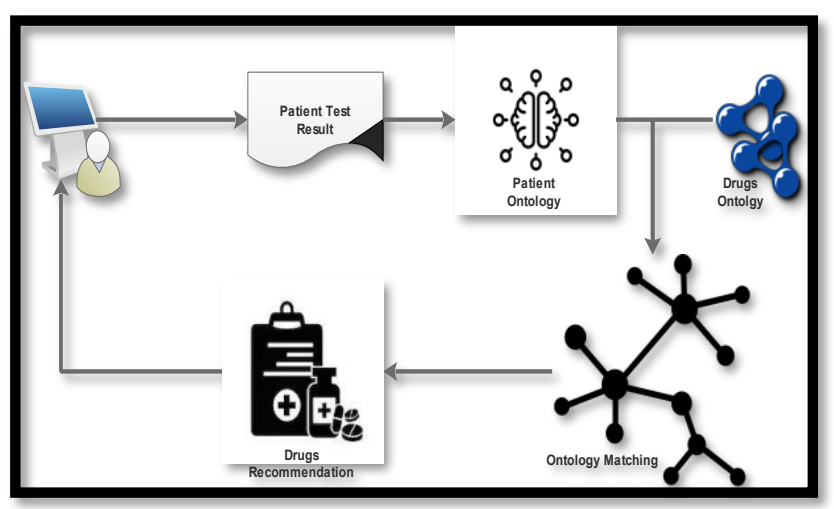

Fig. 1. System architecture

\section{A. Weight Ontology}

According to [19] the weight calculation of an ontology concept is based on density factor. The more a concept is related to other concepts, the bigger weight a concept has. The Weight calculation formula in the ontology concept is:

$$
W_{(c)}=\frac{\text { in degree }(c)+\text { in degree }(p)}{\text { in degree }(o)+\text { out degree }(o)}
$$

W (c) is the weight of concept c. in degree (c) is a relationship that goes into and out-degree(c) concept $\mathrm{c}$ is a relation that out of the concept (c) making the (c) a parent concept (p). in degree (O) is the total number of relationships that led to the concept of layers and outdegree $(\mathrm{O})$ is the number of relationships that leave the layer. Example ontology for weight calculation is shown in Figure 2.

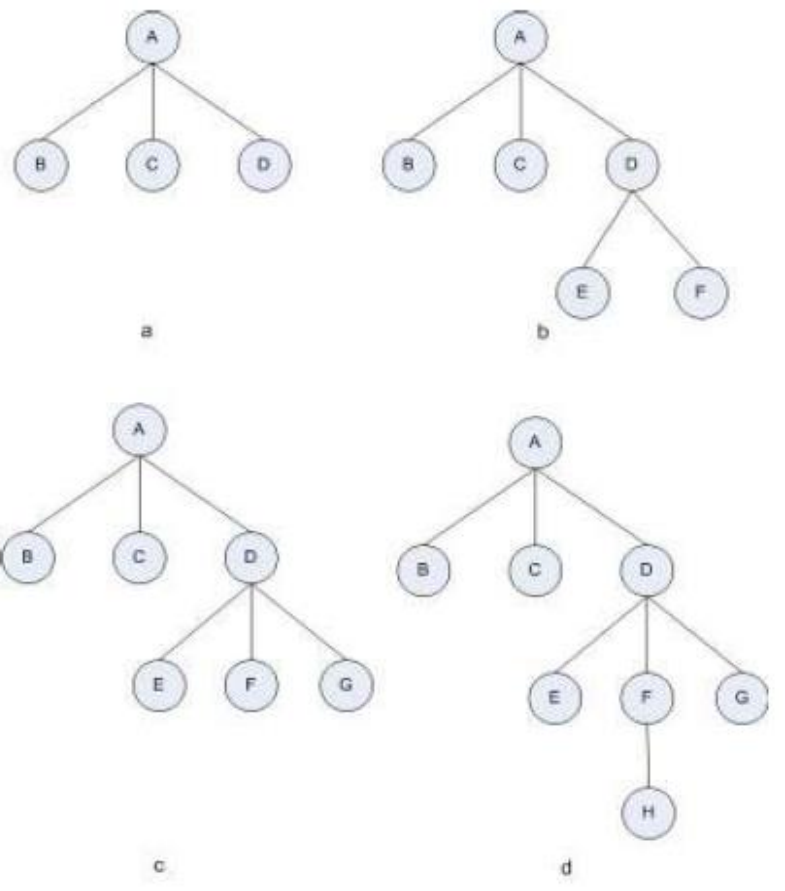

Fig. 2. Weight calculation

Weights for ontology Figure 2 (a)

$$
\begin{gathered}
w(A)=1 \\
w(B)=\frac{1+0}{3+0}=\frac{1}{3}
\end{gathered}
$$$$
\begin{aligned}
& w(C)=\frac{1+0}{3+0}=\frac{1}{3} \\
& w(D)=\frac{1+0}{3+0}=\frac{1}{3}
\end{aligned}
$$

Weights for ontology Figure 2 (b)

$$
\begin{gathered}
w(A)=1 \\
w(B)=\frac{1+0}{3+2}=\frac{1}{5} \\
w(C)=\frac{1+0}{3+2}=\frac{1}{5}
\end{gathered}
$$


Weights for ontology Figure 2 (c)

$$
\begin{gathered}
w(A)=1 \\
w(B)=\frac{1+0}{3+3}=\frac{1}{6} \\
w(C)=\frac{1+0}{3+3}=\frac{1}{6} \\
w(D)=\frac{1+3}{3+3}=\frac{4}{6}
\end{gathered}
$$

$$
\begin{aligned}
& w(E)=\frac{1+0}{3+0}=\frac{1}{3} \\
& w(F)=\frac{1+0}{3+0}=\frac{1}{3} \\
& w(G)=\frac{1+0}{3+0}=\frac{1}{3}
\end{aligned}
$$

Weights for ontology Figure 2 (d)

$$
\begin{array}{cl}
w(A)=1 & w(B)=\frac{1+0}{3+3}=\frac{1}{6} \\
w(C)=\frac{1+0}{3+3}=\frac{1}{6} & w(F)=\frac{1+1}{3+1}=\frac{2}{4} \\
w(D)=\frac{1+3}{3+3}=\frac{4}{6} & w(G)=\frac{1+0}{3+1}=\frac{1}{4} \\
w(E)=\frac{1+0}{3+1}=\frac{1}{4} & w(H)=\frac{1+0}{1+0}=1
\end{array}
$$

From the calculation, it can be concluded that the more a concept is related to other concepts, the greater the weight of the concept.

\section{B. Ontology Matching}

The Matching operation shows alignment $A^{\prime}$ for a pair of ontology o and o'. Some parameters can expand the definition of the matching process. There are the parameters of the use of input alignment $\mathrm{A}$, the matching parameters (such as weights and threshold values), external sources used for the matching process.

The matching process can be considered as a function $f$. Of the pair to be matched ontology o and o ', an alignment $\mathrm{A}$, a set of parameters $\mathrm{p}$ and $\mathrm{r}$ generate resource alignment $\mathrm{A}^{\prime}$. $\mathrm{A}$ ' $=f(\mathrm{o}, \mathrm{o}, \mathrm{A}, \mathrm{p}, \mathrm{r})$.

In the scheme shown in Figure 11, there are more than two ontology matching called multiple matching. Some ontology matching processes can be considered as a function $\mathrm{f}$ which is an ontology matching $\{01, \ldots, \mathrm{on}\}$. An input alignment $\mathrm{A}$, a set of parameters $\mathrm{p}$, and a resource $\mathrm{r}$ produced an alignment $\mathrm{A}^{\prime}$ between the ontology [13]. A '. $\mathrm{A}^{\prime}=f\left(\mathrm{o}, \mathrm{o}^{\prime}, \mathrm{A}, \mathrm{p}, \mathrm{r}\right)$.

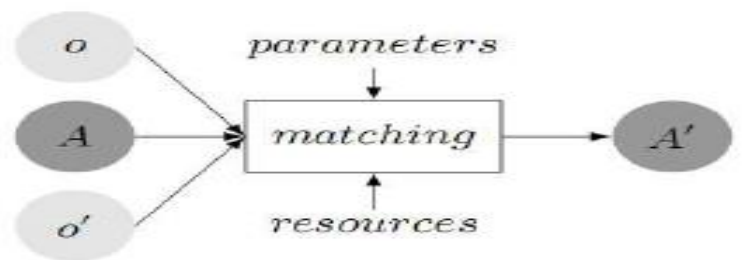

Fig. 3. Ontology matching process [20].

\section{Domain Ontology}

Domain ontology describes all terminology in diabetesrelated clinical guidelines. The purpose of this ontology is to describe the axioms used in the rules for further processing. Figure 4 shows the ontology of the domain.

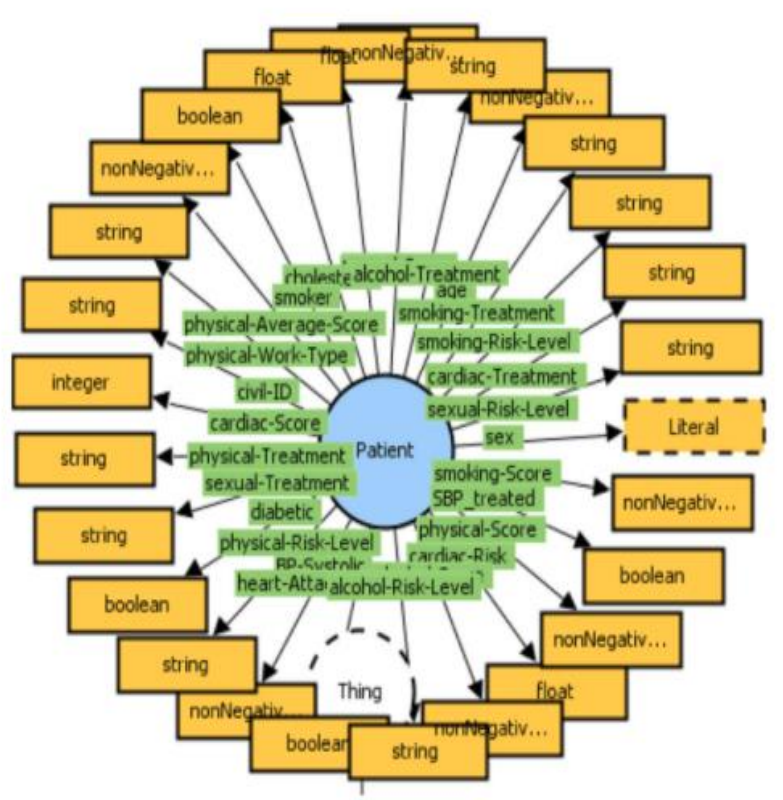

Fig. 4. Domain ontology.

\section{Semantic Profile}

The semantic profile is an OWL file that summarizes patient details, medications, and contraindications. The file was created after the patient submitted his health condition. then the file is matched with the drug file to produce drug recommendations for patients. A patient ontology consists of all patient records stored in the form of ontology. Each patient is an individual (instance) of this ontology and is automatically generated.

\section{EXPERIMENT RESULT}

\section{A. Ontology Model}

The ontology is built by using protégé. Protégé is a free and open-source tool used to build an ontology. Protégé can be extended to build Java-based applications based on ontology.

Figure 5 shows the knowledge processing from drugs and patient tests. The models of drugs ontology are developed into 4 ontologies [14]:

1. Drugs ontology for disease DM Type 1.

2. Drugs ontology for disease DM Type 2 with contraindications.

3. Drugs ontology for disease DM Type 2 without contraindications.

4. Drugs ontology for disease Gestational DM. 


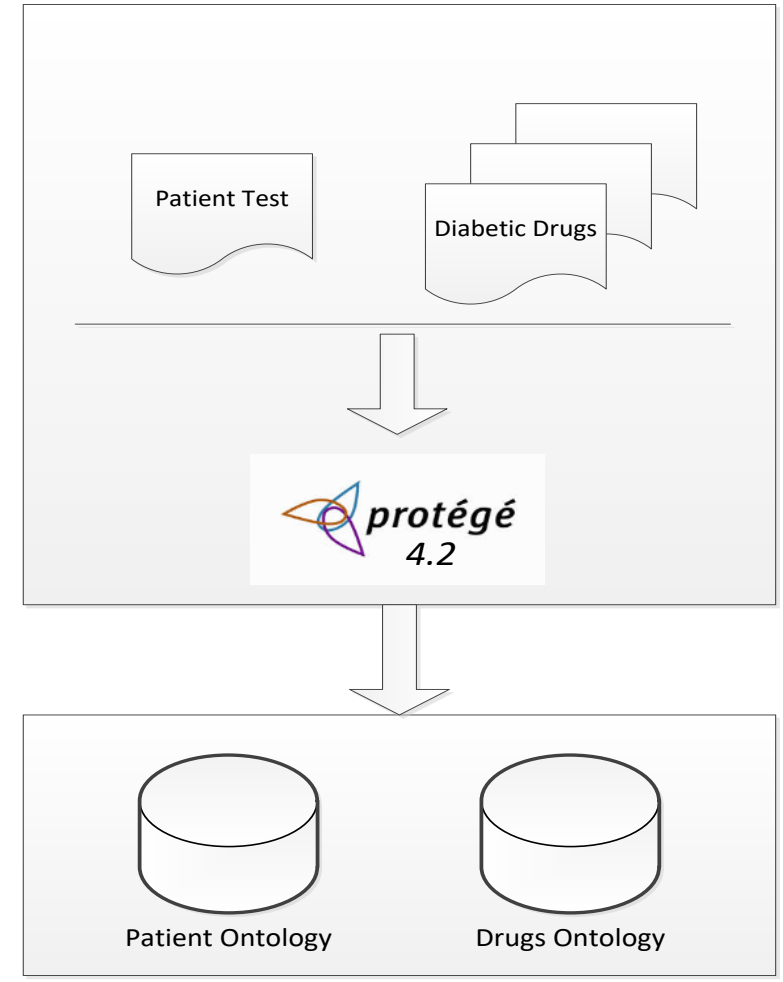

Fig. 5. Knowledge processing.

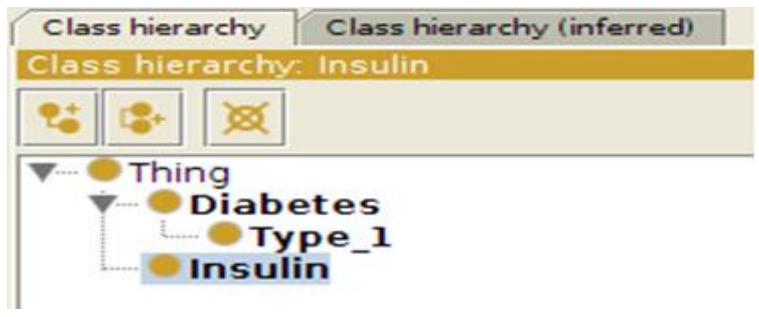

Fig. 6. Drugs ontology for disease DM Type 1

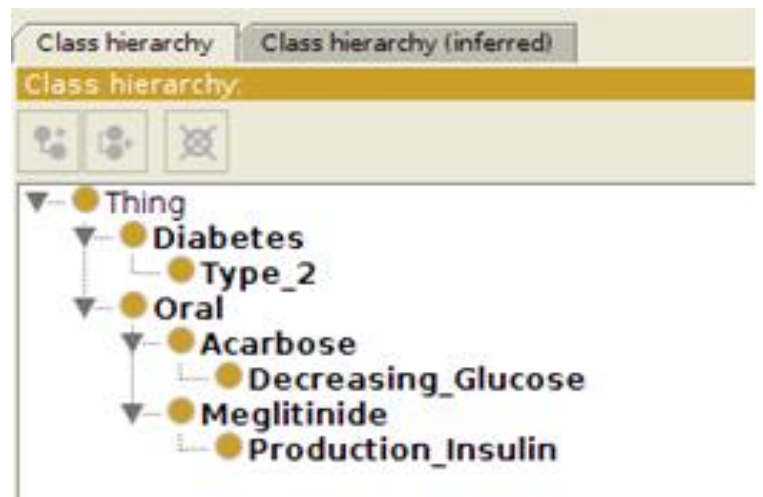

Fig. 7. Drugs ontology for disease DM Type 2 without contraindications.

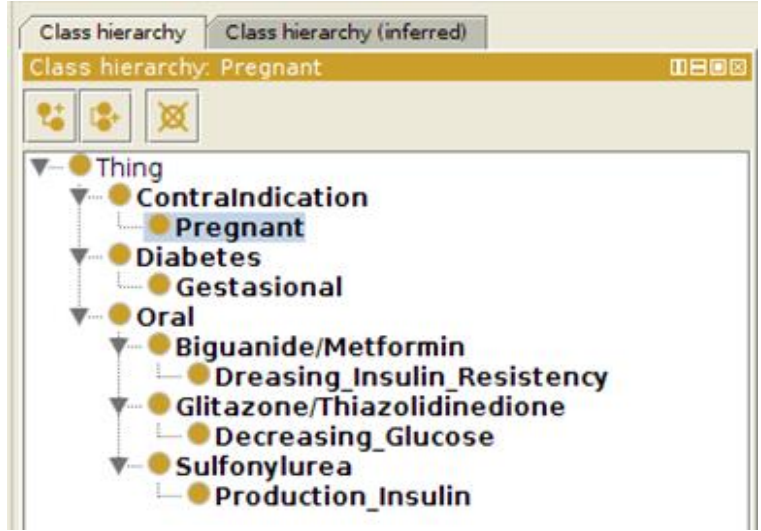

Fig. 8. Drugs ontology for disease DM Gestational.

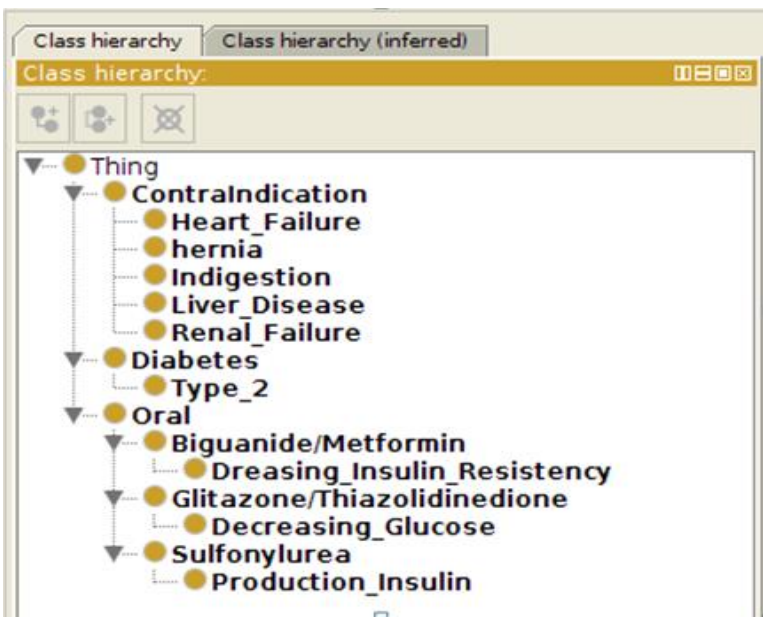

Fig. 9. Drugs ontology for disease DM Type 2 with contraindications.

\section{B. Weight Ontology.}

Weight ontology calculates the weight of each concept for each ontology, and it is based on density shown in Table I. For example, DM Type 1 ontology is shown in Figure 10:

- "Diabetes" has in degree $(c)=1$, out degree $(p)=1$, in degree $(o)=2$, and out degree $(o)=1$, so the weight of a concept "Diabetes" calculated by using formula (1) is $2 / 3=0.66$,

- "Insulin" has in degree $(c)=1$, out degree $(p)=0$, in degree $(o)=2$, and out degree $(o)=1$, so the weight of a concept "Diabetes" calculated by using formula (1) is $1 / 3=0.33$,

- "Type 1 " has in degree $(c)=1$, out degree $(p)=0$, in degree $(o)=1$, and out degree $(o)=0$, so the weight of a concept "Diabetes" calculated by using formula (1) is $1 / 1=1.00$. 


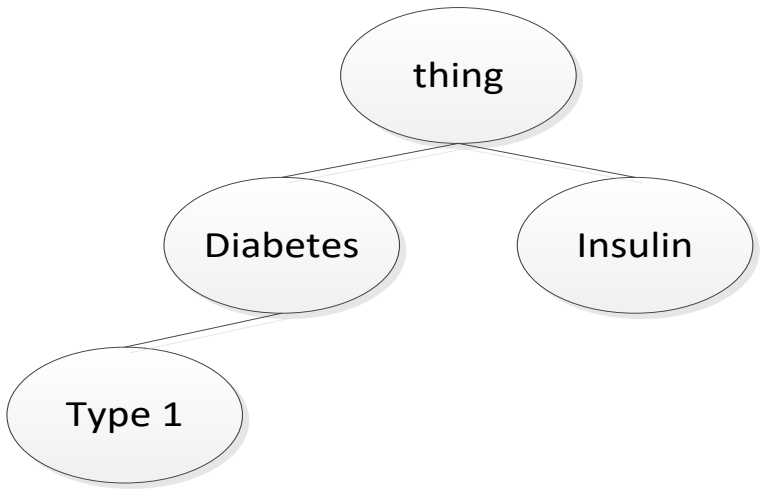

Fig. 10. DM Type 1 ontology.

TABLE I. The Weight of EACH CONCEPT FOR EACH ONTOLOGY.

\begin{tabular}{|c|c|c|}
\hline Ontology & Concept & Weight \\
\hline DM Type 1 & $\begin{array}{l}\text { Diabetes } \\
\text { Type_1 } \\
\text { Insulin }\end{array}$ & $\begin{array}{l}0.66 \\
1.00 \\
0.33 \\
\end{array}$ \\
\hline $\begin{array}{l}\text { DM Type } 2 \text { without } \\
\text { Contraindications }\end{array}$ & $\begin{array}{l}\text { Diabetes } \\
\text { Type_2 } \\
\text { Oral } \\
\text { Meglitinide } \\
\text { Production_Insulin } \\
\text { Acarbose } \\
\text { Decreasing_Glucose }\end{array}$ & $\begin{array}{l}0.40 \\
1.00 \\
0.60 \\
0.50 \\
1.00 \\
0.50 \\
1.00\end{array}$ \\
\hline $\begin{array}{l}\text { DM Type } 2 \text { with } \\
\text { Contraindications }\end{array}$ & $\begin{array}{l}\text { Diabetes } \\
\text { Type_2 } \\
\text { Oral } \\
\text { ContraIndication } \\
\text { Heart_Failure } \\
\text { Hernia } \\
\text { Renal_Failure } \\
\text { Liver_Disease } \\
\text { Indigestion } \\
\text { Metformin } \\
\text { Thiazolidinedione } \\
\text { Sulfonylurea } \\
\text { Decreasing_Glucose } \\
\text { Dreasing_Insulin_Resistency } \\
\text { Production_Insulin }\end{array}$ & $\begin{array}{l}0.16 \\
1.00 \\
0.33 \\
0.43 \\
0.20 \\
0.20 \\
0.20 \\
0.20 \\
0.20 \\
0.33 \\
0.33 \\
0.33 \\
1.00 \\
1.00 \\
1.00\end{array}$ \\
\hline DM Gestational & $\begin{array}{l}\text { Diabetes } \\
\text { Oral } \\
\text { Contraindication } \\
\text { Pregnant } \\
\text { Metformin } \\
\text { Thiazolidinedione } \\
\text { Sulfonylurea } \\
\text { Decreasing_Glucose } \\
\text { Dreasing_Insulin_Resistency } \\
\text { Production_Insulin }\end{array}$ & $\begin{array}{l}0.25 \\
0.50 \\
0.25 \\
1.00 \\
0.33 \\
0.33 \\
0.33 \\
1.00 \\
1.00 \\
1.00\end{array}$ \\
\hline
\end{tabular}

\section{Ontology Matching}

The ontology matching Similarity $\left(\mathrm{Q}, \mathrm{D}_{\mathrm{j}}\right)$ is done by using the formula:

$$
\operatorname{sim}\left(Q, D_{j}\right)=\frac{\sum_{\mathrm{j}=1}^{\mathrm{t}} \mathrm{q}_{\mathrm{j}} \mathrm{di}_{\mathrm{j}}}{\sqrt{\sum_{\mathrm{j}=1}^{\mathrm{t}}\left(\mathrm{q}_{\mathrm{j}}\right)^{2} \sum_{\mathrm{j}=1}^{\mathrm{t}}\left(\mathrm{d}_{\mathrm{ij}}\right)^{2}}}
$$

In which:

- $\mathrm{Q}$, is the ontology of patient

- $\mathrm{D}_{\mathrm{j}}$, is the ontology drugs

- $\mathrm{q}_{\mathrm{j}}$, is a weight of concept $(\mathrm{j})$ the ontology patient

- $\mathrm{d}_{\mathrm{ij}}$, is a weight of concept $(\mathrm{i}, \mathrm{j})$ the ontology drugs.

For example, patients with ontology as shown in Figure 11 will be matched with drugs that have been previously weighted in which ontologies that have a high similarity value will be a solution of the drugs to the patient's recommendation. Formula (2) is used to calculate the similarity of the patient ontology and drugs ontology. The weight of each concept which has been calculated using the Formula (1) is used to weigh the concepts $\left(d_{i j}\right)$. Calculating the similarity between patients ontology with drugs ontology DM Type 1 is shown in Table II, calculating the similarity between patients ontology with drugs DM Type 2 Without Contraindication ontology is shown in Table III, calculating the similarity between patients ontology with drugs DM Type 2 With Contraindication ontology is shown in Table IV, and calculating the similarity between patients ontology with drugs DM Gestational ontology is shown in Table V.

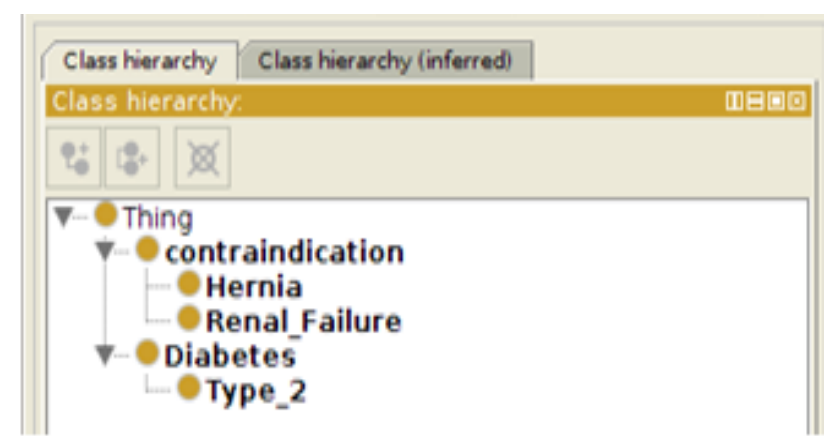

Fig. 11. Patient ontology.

TABLE II. COMParing ONTOLOGY PATIENTS With ONTOLOGY DRUGS FOR DM TYPE 1.

\begin{tabular}{|l|c|l|c|}
\hline \multicolumn{2}{|c|}{ Patient Ontology } & \multicolumn{2}{c|}{ Drugs Ontology } \\
\hline \multicolumn{1}{|c|}{ Concept } & Weight & \multicolumn{1}{c|}{ Concept } & Weight \\
\hline Diabetes & 0.2 & Diabetes & 0.20 \\
Type_2 & 0.3 & Not Found & - \\
Contraindication & 0.1 & Not Found & - \\
Hernia & 0.1 & Not Found & - \\
Renal_Failure & 0.1 & Not Found & - \\
\hline
\end{tabular}

Similarity result calculate used formula $(2)=0.50$ 


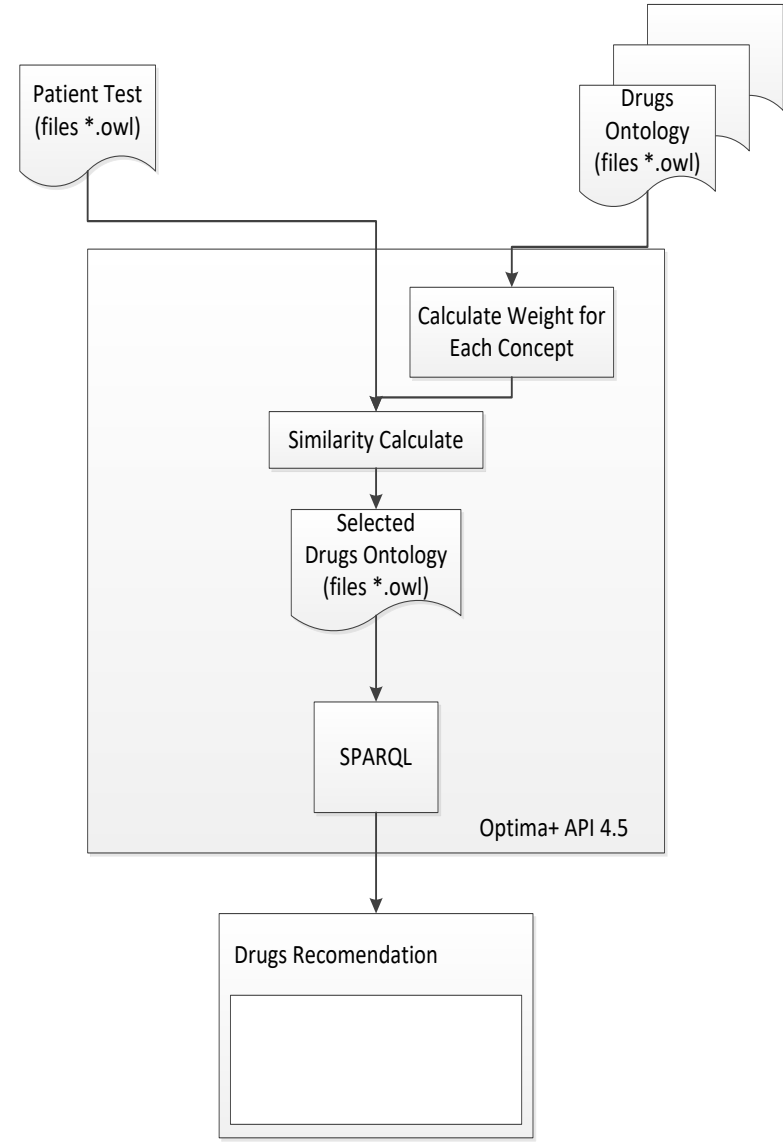

Fig. 12. Construct anti-diabetic drugs system.

TABLE III. COMParing Ontology Patients With OnTOLOGY DRUGS FOR DM TYPE 2 WITHOUT CONTRAINDICATION.

\begin{tabular}{|l|c|l|c|}
\hline \multicolumn{2}{|c|}{ Patient Ontology } & \multicolumn{2}{c|}{ Drugs Ontology } \\
\hline \multicolumn{1}{|c|}{ Concept } & Weight & \multicolumn{1}{|c|}{ Concept } & Weight \\
\hline Diabetes & 0.2 & Diabetes & 0.40 \\
Type_2 & 0.3 & Type_2 & 1.00 \\
Contraindication & 0.1 & Not Found & - \\
Hernia & 0.1 & Not Found & - \\
Renal_Failure & 0.1 & Not Found & - \\
& & & \\
\hline
\end{tabular}

Similarity result calculate used formula $(2)=0.88$

TABLE IV. COMPARING ONTOLOGY PATIENTS WITH ONTOLOGY DRUGS FOR DM TYPE 2 WITH CONTRAINDICATION.

\begin{tabular}{|l|c|l|c|}
\hline \multicolumn{2}{|c|}{ Patient Ontology } & \multicolumn{2}{c|}{ Drugs Ontology } \\
\hline \multicolumn{1}{|c|}{ Concept } & Weight & \multicolumn{1}{|c|}{ Concept } & Weight \\
\hline Diabetes & 0.2 & Diabetes & 0.16 \\
Type_2 & 0.3 & Type_2 & 1.00 \\
Contraindication & 0.1 & Contraindication & 0.43 \\
Hernia & 0.1 & Hernia & 0.20 \\
Renal_Failure & 0.1 & Renal_Failure & 0.20 \\
& & & \\
& & & \\
\hline
\end{tabular}

Similarity result calculate used formula $(2)=0.91$
TABLE V. COMPARING ONTOLOGY PATIENTS WITH ONTOLOGY DRUGS FOR DM GESTATIONAL.

\begin{tabular}{|l|c|l|c|}
\hline \multicolumn{2}{|c|}{ Patient Ontology } & \multicolumn{2}{c|}{ Drugs Ontology } \\
\hline \multicolumn{1}{|c|}{ Concept } & Weight & \multicolumn{1}{c|}{ Concept } & Weight \\
\hline Diabetes & 0.2 & Diabetes & 0.25 \\
Type_2 & 0.3 & Not Found & - \\
Contraindication & 0.1 & Contraindication & 0.25 \\
Hernia & 0.1 & Not Found & - \\
Renal_Failure & 0.1 & Not Found & - \\
\hline
\end{tabular}

Similarity result calculate used formula $(2)=0.53$

The calculation results of the ontological similarity process showed that patient ontology and contraindicated drugs ontology have a high similarity value which is 0.91 .

\section{Construct the anti-diabetic drugs system.}

An anti-diabetic system is built using java by adding library optima+ API 4.5 By the system architecture in Figure 1, the construction system of anti-diabetic is shown in Figure 12. the system comprises a sequence of processes as follows, calculate the weight of each concept of drugs ontology, calculate the similarity of the patient ontology with each drugs ontology, and the last drugs ontology that has the highest similarity is selected as the solution and using SPARQL to get the instances from Ontology and then show it is like shown Figure 13.

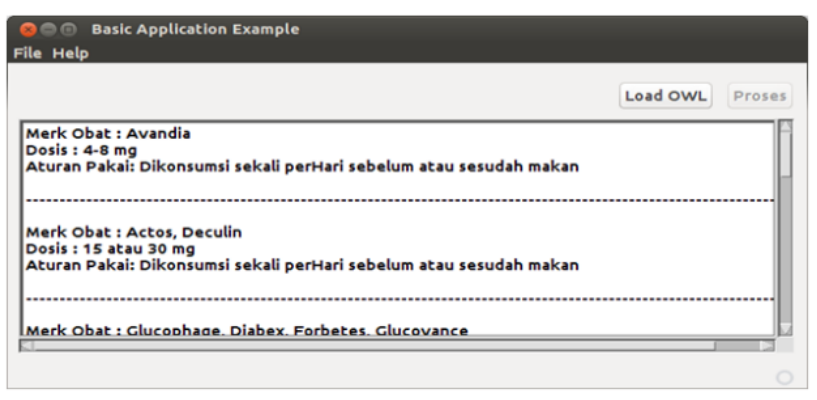

Fig. 13. Result drugs recommendation.

\section{E. The evaluation of anti-diabetic drugs system}

System accuracy is very important for anti-diabetic drugs system. We used the system for recommendation drugs and let the expert evaluate the system. The system used 12 data tests to evaluate and check precision.

In Table VI, True Positive Rate (TP) if the expert agrees on the recommendation drugs and False Negative if the expert disagrees on the recommendation drugs. The precision rate is calculated by the Formula (3).

TABLE VI. The Precision Rate Estimation.

\begin{tabular}{|c|c|}
\hline Parameter & Definition \\
\hline True Positive Rate (TP) & $\begin{array}{c}\text { The expert agrees on } \\
\text { recommendation drugs. }\end{array}$ \\
\hline False Negative Rate (FN) & $\begin{array}{l}\text { The Expert disagrees on } \\
\text { recommendation drugs }\end{array}$ \\
\hline
\end{tabular}


TABLE VII. The Data of Twenty Patients.

\begin{tabular}{|c|c|c|c|c|c|c|}
\hline No & $\begin{array}{c}\text { Diabet } \\
\text { es }\end{array}$ & $\begin{array}{c}\text { Heart } \\
\text { Failure }\end{array}$ & Hernia & $\begin{array}{c}\text { Renal } \\
\text { Failur } \\
\text { e }\end{array}$ & $\begin{array}{c}\text { Liver } \\
\text { Diseas } \\
\text { e }\end{array}$ & $\begin{array}{c}\text { Indis } \\
\text { gatio } \\
n\end{array}$ \\
\hline 1 & Type 1 & 0 & 0 & 0 & 1 & 1 \\
\hline 2 & Type 1 & 1 & 0 & 1 & 0 & 1 \\
\hline 3 & Type 1 & 0 & 0 & 0 & 0 & 0 \\
\hline 4 & Type 1 & 0 & 1 & 0 & 1 & 0 \\
\hline 5 & Type 2 & 0 & 0 & 0 & 0 & 0 \\
\hline 6 & Type 2 & 0 & 0 & 1 & 0 & 1 \\
\hline 7 & Type 2 & 1 & 1 & 1 & 0 & 0 \\
\hline 8 & Type 2 & 0 & 1 & 0 & 1 & 1 \\
\hline 9 & $\begin{array}{l}\text { Gestatio } \\
\text { nal }\end{array}$ & 0 & 0 & 0 & 0 & 0 \\
\hline 10 & $\begin{array}{l}\text { Gestatio } \\
\text { nal }\end{array}$ & 1 & 0 & 1 & 0 & 0 \\
\hline 11 & $\begin{array}{l}\text { Gestatio } \\
\text { nal }\end{array}$ & 1 & 0 & 0 & 1 & 0 \\
\hline 12 & $\begin{array}{l}\text { Gestatio } \\
\text { nal }\end{array}$ & 0 & 1 & 0 & 1 & 1 \\
\hline
\end{tabular}

$$
\text { Precision }=\frac{T P}{T P+F N}
$$

$$
\begin{aligned}
& \text { Recommend Drugs Rate = } \\
& \frac{\text { Total number of ayatem recommend drugs }}{\text { Total Number of recommend drugs of expert }} \\
& 100 \%
\end{aligned}
$$

Formula (4) is used to estimate the effectiveness of an anti-diabetic drugs system. The result of the test is shown a precision rate of $100 \%$. The result of this study is good because the system can recommend drugs that match the expert.

\section{CONCLUSIONS}

With large options of diabetes medications that can be consumed, a system can be developed to assist diabetes experts in recommending a diabetes drug that has to be consumed by diabetics. By doing ontology matching, obtained results show that the ontology that has the highest similarity might be a reference to solve the problems in a particular domain. The calculation results of the ontological similarity process showed that patient ontology and contraindicated drugs ontology have a high similarity value which is 0.91 , and it is selected as a solution. The result of this study is good because the system can recommend drugs that match the expert.

\section{REFERENCES}

American Diabetes Association (ADA). "National Diabetes $\quad$ Fact 2011. http://www.cdc.gov/diabetes/pubs/pdf/ndfs_2011.pdf.

[2] Sudoyo, A. "Buku Ajar Ilmu Penyakit Dalam". Jakarta : FKUI. 2006.

[3] Pramono, D., Setiawan, N.Y., Sarno, R. \& Sidiq, M.” Physical Activity Recommendation for Diabetic Patients Based on Ontology". The 7th International Conference on Information \& Communication Technology and Systems (ICTS) 2013. May 15-16, 2013. Bali, Indonesia.

[4] Huang, T.Y. "An Ontology Approach to Modeling the Drugs Guideline for Dyslipidemia Drugs of Bureau of
National Health Insurance". Master Thesis, Graduate Institute of Medical Informatics of Taipei Medical University. 2003.

[5] Jovic, A., Prcela, M., \& Gamberger, D. "Ontologies in medical knowledge representation". Information Technology Interfaces. 2007. Pages 535-540.

[6] Zhang, G., Jia, S., \& Wang, Q. "Construct ontology-based enterprise information metadata framework". Journal of Software, Vol5-3. 2010. pages 312-319.

[7] Sarno, R., Anistyasari, Y. and Fitri, R. "Semantics Search : Pencarian Berdasarkan Konten”. Yogyakarta. Andi. 2012.

[8] Anistyasari, Y. \& Sarno, R. "Weigthed Ontology for Subject Search in Learning Content Management System". Bandung. IEEE. 2011. pp. 1 - 4.

[9] Saadah, U., Sarno, R., and Yuhana, U.L. "Latent Semantic Analysis and Weighted Tree Similarity for Semantic Search in Digital Library". The 7th International Conference on Information \& Communication Technology and Systems (ICTS) 2013. May 15-16, 2013. Bali, Indonesia.

[10] Sarno, R., Ghozali, K., Nugroho, B. A. \& Hijriani, A. "Semantic Matchmaking using Weighted Directed Acyclic Graph". Surabaya, Institut Teknologi Sepuluh Nopember (ITS). 2011. pp. 1-6.

[11] Lv, G. and Zheng, C.. "Text information Retrieval Based on Concept Semantic Similarity". Fifth International Conference on Semantics, Knowledge, and Grid. 2009. pages. 356-360.

[12] L. Chen et al., "OMDP: An ontology-based model for diagnosis and treatment of diabetes patients in remote healthcare systems," Int. J. Distrib. Sens. Networks, vol. 15, no. 5, May 2019, doi: 10.1177/1550147719847112.

[13] P. C. Sherimon and R. Krishnan, "OntoDiabetic: An Ontology-Based Clinical Decision Support System for Diabetic Patients," Arab. J. Sci. Eng., vol. 41, no. 3, pp. 1145-1160, Mar. 2016, doi: 10.1007/s13369-015-1959-4.

[14] S. Quinn, R. Bond, and C. Nugent, "A two-staged approach to developing and evaluating an ontology for delivering personalized education to diabetic patients," Informatics Heal. Soc. Care, vol. 43, no. 3, pp. 264-279, Jul. 2018, doi: 10.1080/17538157.2017.1364246.

[15] R. C. Chen, Y. H. Huang, C. T. Bau, and S. M. Chen, "A recommendation system based on domain ontology and SWRL for anti-diabetic drugs selection," Expert Syst. Appl., vol. 39, no. 4, pp. 3995-4006, Mar. 2012, doi: 10.1016/j.eswa.2011.09.061.

[16] C. T. Bau, R. C. Chen, and C. Y. Huang, "Construction of a clinical decision support system for undergoing surgery based on domain ontology and rules reasoning," Telemed. e-Health, vol. 20, no. 5, pp. 460-472, May 2014, doi: 10.1089/tmj.2013.0221.

[17] R. D. Dewandono, R. Fauzan, R. Sarno, and M. Sidiq, "Ontology and Process Mining for Diabetic Medical Treatment Sequencing," 7th Int. Conf. Inf. Commun. Technol. Syst., pp. 171-178, 2013.

[18] Arwan, M. Sidiq, B. Priyambadha, H. Kristianto, and R. Sarno, "Ontology and semantic matching for diabetic food recommendations," in Proceedings - 2013 International Conference on Information Technology and Electrical Engineering: "Intelligent and Green Technologies for Sustainable Development", ICITEE 2013, 2013, pp. 170175, doi: 10.1109/ICITEED.2013.6676233. 
[19] L. Toruan, Phaidon. and Andriani Kaswara, Rani. "Fat-loss Not Weight-loss for Diabetes : Sakit Tapi Sehat". Jakarta. Transmedia. 2012.
[20] Euzenat, J. and Shvaiko, P. “Ontology Matching". Trento: Springer. 2007. 